and refrigeration have been required for prolonged preservation. Brettschneider et al. (1968) were able to preserve dog livers consistently for eight hours. Over the last four years much effort has been expended in our laboratory to obtain consistent and prolonged preservation of the liver. Until recently the best result obtained in pigs was seven hours of preservation by using an initial cold flush and then storage in ice (Hadjiyannakis et al., 1971). This was tested by orthotopic allografting. The technique described here has permitted the storage time to be increased to 17 hours, and in the last six consecutive experiments five animals survived the procedure with good liver function. We feel that the failures have been due to technical errors either in the surgery or in the perfusion.

In one preliminary experiment where the perfusion failed owing to a mechanical fault, although the liver was kept at $4^{\circ} \mathrm{C}$ throughout the preservation, its consistency was grossly abnormal at the time of transplantation. It was very soft, and disintegrated when handled gently. This observation together with previous experience with non-perfused livers and the consistent finding of oxygen utilization by the livers during preservation indicate that the perfusion plays an essential part in the increased preservation times. The pig's liver is very susceptible to temperature changes during preservation, and if the temperature is inadvertently allowed to rise above $5^{\circ}$ damage occurs and the organ fails to support life.

Single passage perfusion of kidneys was reported by Hermann and Turcotte (1969). The advantages of this system are that no filters are necessary, constituents in the perfusate cannot be exhausted, waste products are removed, and the apparatus is simple. Turner and Alican (1970) found that canine liver preservation was better when the $\mathrm{pH}$ of the perfusate was 7 as opposed to 7.4. The perfusate that we used consisted of a basis of human plasma, the protein fraction being mainly albumin. The added potassium, phosphate, and magnesium alter the electrolyte content towards that of intracellular fluid. $\mathrm{A} \mathrm{pH}$ of 6.8 is probably close to the $\mathrm{pH}$ within the cell. We feel that the intermittent squirting of the perfusate not only has advantages of parenchymal perfusion due to the pressure achieved with each bolus, but also in the interval between perfusion there is an opportunity for osmotic equilibrium to occur. It has been notable that significant weight change of the liver during preservation has not been observed. The disadvantages of this technique are that it is extravagant in the use of perfusate, some 4 litres being required for 17 hours' preservation, and essential cellular constituents could be washed out of the liver.

It is possible to modify the perfusion by analysis of the difference of the constituents in the perfusate compared with those in the venous effluent. Estimations so far of electrolytes, aminoacids, fatty acids, and dextrose show no significant change. There is, however, a consistent alteration of $\mathrm{pO}_{2}$ indicating oxygen consumption by the preserved organ. No attempts were made to oxygenate the perfusate, which had a $\mathrm{pO}_{2}$ of between 100 and $160 \mathrm{~mm} \mathrm{Hg}$ while the $\mathrm{pO}_{2}$ of the effluent was under $50 \mathrm{~mm} \mathrm{Hg}$. We are modifying the apparatus so that it can be transportable, and hope that application to man will allow us to transport livers from other institutions to our own hospital where clinical liver transplantation can be performed without having to move the sick patient.

We wish to thank the biochemistry department of the John $\underset{\omega}{\mathscr{W}}$ Bonnett Clinical Laboratories for performing many of the esti- $\overrightarrow{-}$ mations, Dr. David Bowyer for assays of free fatty acid, and Mrs. $M$. Sheldon and the department of medical illustration for preparing the Figure.

\section{References}

Belzer, F. O., Ashby, B. S., and Dunphy, J. E. (1967). Lancet, 2, 536

Brettschneider, L., et al. (1968). Surgery, Gynecology and Obstetrics, 126, 265. Calne, R. Y., and Williams, R. (1968). British Medical fournal, 4, 535.

Calne, R. Y., Yoffa, D. E., White, H. J. O., and Maginn, R. R. (1968). British Fournal of Surgery, 55, 203.

Calne, R. Y., Dunn, D. C., Gajo-Reyero, R., Hadjiyannakis, E. J., and Robson, A. J. (1972). Nature, 235, 171

Collins, G. M., Bravo-Shugarman, M., and Terasaki, P. I. (1969). Lancet, 2, 1219.

Hadjiyannakis, E. J., Calne, R. Y., Marshall, V. C., and Davis, D. R. (1971) British fournal of Surgery, 58, 835.

Hermann, T. J., and Turcotte, J. G. (1969). Archives of Surgery, 98, 121.

Schalm, S. W. (1968). Ph.D. Thesis, University of Leiden, Leiden, Holland. D Turner, M. D., and Alican, F. (1970). Cryobiology, 6, 293.

\title{
Fingerprints in Patients with Coeliac Disease and their Relatives
}

\section{MYLOTTE, B. EGAN-MITCHELL, P. F. FOTTRELL, B. McNICHOLL, C. F. McCARTHY}

British Medical fournal, 1972, 4, 144-146

\section{Summary}

The incidence of fingerprint pattern abnormality in 53 patients with coeliac disease and 82 of their relatives was not greater than that found in 58 control subjects. This finding contradicts an earlier report that most patients with coeliac disease had abnormal fingerprints.

\section{Regional Hospital, Galway, Eire}

M. MYLOTTE, M.B., B.A.o., Research Fellow

B. EGAN-MITCHELL, M.B., D.C.H., Research Fellow

B. MCNICHOLL, M.D., F.R.C.P., Paediatrician, and Professor of Paediatrics, B. MCNICHOLL, M.D., F.R.C.P.

C. F. McCARTHY, M.D., F.R.c.P.I., Physician, and Associate Professor of F. MCCARTHY, M.D., F.R.C.P.I., Phy
Medicine, University College, Galway

University College, Galway, Eire

P. F. FOTTRELL, M.sC., PH.D., Associate Professor of Biochemistry

\section{Introduction}

The description by David and colleagues (1970) of abnormal fingerprint patterns in most patients with coeliac disease 0 aroused considerable interest not only in medical circles but $\omega$ also in police departments (Sunday Express, 1971). Since then a

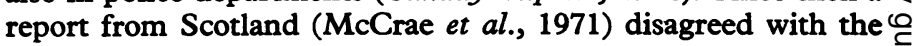
findings and showed that fingerprints are normal in coeliacs. $\mathbb{D}$ Verbov et al. (1971) found no evidence of epidermal ridge ?atrophy in 37 patients with dermatitis herpetiformis. In an attempt to resolve this discrepancy, fingerprint examinations were carried out on coeliac patients and on their first-degree relatives who were being studied for other reasons (Mylotte $\stackrel{\mathbb{Q}}{\square}$ et al., 1972). Fingerprints taken from patients undergoing gastrointestinal investigation and hospital staff were used as $\delta$ controls.

\section{Subjects and Methods}

Altogether 53 patients with coeliac disease, 18 males and 35 females, were studied. All had subtotal villous atrophy of the 
proximal small intestinal mucosa at the time of diagnosis of coeliac disease. Twenty-two of the 53 were under the age of 12 years. Favourable clinical response to gluten-free diet was noted in all. The time relationship of fingerprint examination to stage of treatment is given in Table $I$.

TABLE I-Relationship of Therapy to Fingerprint Pattern

\begin{tabular}{|c|c|c|c|c|c|}
\hline \multicolumn{4}{|c|}{ Coeliac Patients } & No. & Fingerprints Normal \\
\hline $\begin{array}{l}\text { Untreated } \\
\text { Fully treated * } \\
\text { Partly treated } \ldots\end{array}$ & $\begin{array}{l}\cdots \\
\cdots\end{array}$ & $\begin{array}{l}\cdots \\
\cdots\end{array}$ & $\begin{array}{l}\cdots \\
\cdots\end{array}$ & $\begin{array}{r}29 \\
15 \\
9\end{array}$ & $\begin{array}{r}23 \\
13 \\
8\end{array}$ \\
\hline
\end{tabular}

Jejunal biopsy almost normal.
+On gluten-free diet for three months or more. No repeat jejunal biopsy.

Fingerprint patterns from the following groups of controls were examined. Twenty-eight patients, including 13 males who were undergoing gastrointestinal investigation. All had normal jejunal mucosa on biopsy. Eight children with a variety of disorders who did not have a jejunal biopsy. Nine male and 13 female hospital and laboratory personnel, 17 of whom were known to have a normal jejunal biopsy. All hospital and laboratory personnel studied gave informed consent for the procedures carried out.

Rolled and plain fingerprint patterns were recorded using the ink and plate method (Home Office, 1960). Ether was not used to clean the fingers.

Method of Analysis.-The records of the fingerprint patterns were examined separately by two of us without knowledge of the type of person from whom the print was recorded. A hand lens was used to study fine detail. Prints were separated into two groups; unequivocably normal (Fig. 1) and "abnormal" (Table II). Slight smudging of fingerprint pattern (Fig. 2) excluded it from the unequivocably normal group. The "abnormal" group was further studied and from it those prints

TABLE II-Fingerprint Abnormality in Coeliacs, their Relatives, and Controls

\begin{tabular}{|c|c|c|c|c|}
\hline & & & $\begin{array}{l}\text { No. } \\
\text { Studied }\end{array}$ & $\begin{array}{l}\text { No. with Normal } \\
\text { Fingerprints }\end{array}$ \\
\hline $\begin{array}{l}\text { Coeliacs.. } \\
\text { Coeliac relatives } \\
\text { Controls }\end{array}$ & $\because$ & $\begin{array}{l}\cdots \\
\cdots \\
\cdots\end{array}$ & $\begin{array}{l}53 \\
82 \\
58\end{array}$ & $\begin{array}{l}44 \\
62 \\
48\end{array}$ \\
\hline
\end{tabular}

which fulfilled the criteria used by David and colleagues (1970) were separated (Table III, Fig. 3). As it seemed possible that practice might improve the definition and clarity of fingerprint recording, in Table IV the results are separated into the first $25 \%$ of print examinations that were carried out and the later $75 \%$.

TABLB In-Types of Abnormality

\begin{tabular}{ll|c|c|c|c}
\hline & $\begin{array}{c}\text { No. } \\
\text { Studied }\end{array}$ & $\begin{array}{c}\text { Non- } \\
\text { specific } \\
\text { Abnormality }\end{array}$ & Slight & Definite \\
\cline { 5 - 6 } & & 53 & 5 & 2 & 2 \\
Coeliacs & $\cdots$ & 82 & 17 & 3 & 0 \\
Relatives & $\cdots$ & 88 & 8 & 0 & 2
\end{tabular}

TABLE IV-Results of Examinations of Fingerprints in First Quarter v. Latter Three quarters of Total Subjects Studied

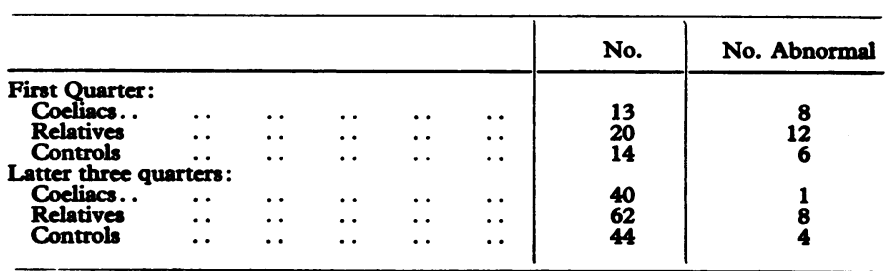

\section{Discussion}

The study shows that over $80 \%$ of coeliac patients in the west of Ireland have normal fingerprint patterns. This finding is in striking contrast to David's finding of $86 \%$ abnormality in Bristol. Indeed the degree of abnormality in the coeliac patients we studied is not different from that in our controls who in most instances were known not to have coeliac disease by reason of a normal jejunal biopsy. The possibility that epidermal ridge atrophy in coeliac disease is restricted to those who develop symptoms in adulthood is excluded by its absence in 10 adult coeliac patients, none of whom had a history of symptoms relating to their childhood. The findings of McCrae et al. (1971) of no abnormality of fingerprint pattern in 23 coeliacs in Edinburgh is more in keeping with the present findings than those of David et al. Our technique differed from
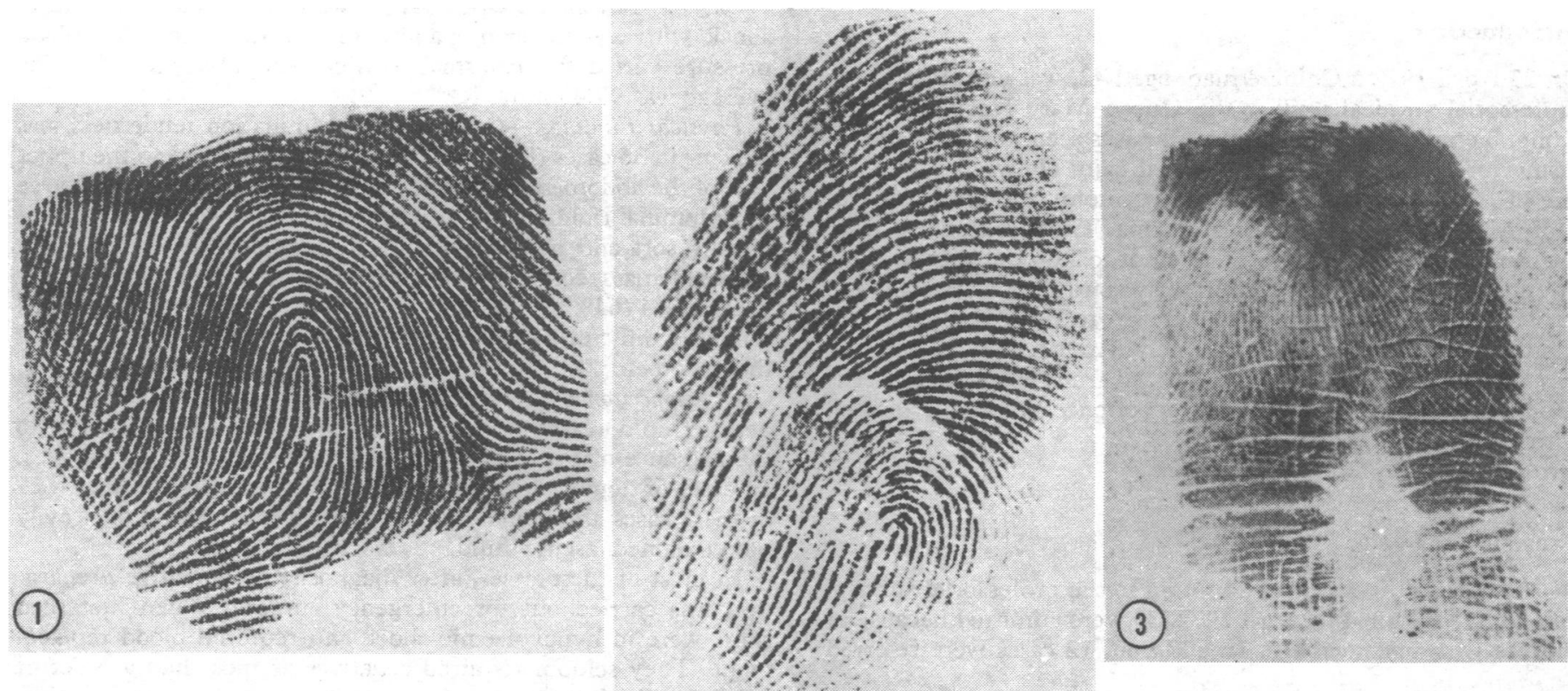

(2)

pIG. 1-Normal fingerprint pattern taken from adult with untreated coeliac disease. FIG. 2-Slight smudging (top half) with patchy areas of absent ridges (bottom half) due to occupational scarring in a coeliac relative. FIG. 3-Example of ridge atrophy from 12-year-old untreated coeliac. On left of pattern there is total ridge atrophy with no ridges discernible. Ridge atrophy on right side is only partial and is accompanied by presence of white lines. 
that used by David et al. (1970) in that he washed the fingers with ether to remove perspiration. Our failure to do so may be partly responsible for the high proportion of minor abnormalities in the patients studied, but does not explain the high percentage of normal fingerprint patterns in the coeliac patients.

One of us (M.M.) is in receipt of a Research Fellowship from the Medical Research Council of Ireland. The work is also supported by the Wellcome Trust. We wish to thank Michael J. Kelly for his invaluable technical and photographical help.

\section{References}

David, T. J., Ajdukiewicz, A. B., and Read, A. E. (1970). British Medical fournal, 4, 594

Home Office (1960). Instructions in the Method of Taking Finger and Palm Prints. London, H.M.S.O.

McCrae, W. Morrice, Sandor, G., Sangani, A. P., and Stalker, R. (1971) British Medical fournal, 3, 109.

Mylotte, M. J., Egan-Mitchell, B., Fottrell, P. F., McNicholl, B., and McCarthy, C. F. (1972). Quarterly fournal of Medicine. To be published.

Sunday Express, 1971, November.

Verbov, Julian, Kumar Parveen, J., and Marks, Ronald (1971). British Medical fournal, 4, 300.

\title{
Spontaneous Rupture of Hepatocellular Carcinoma
}

\author{
G. B. ONG, J. L. TAW
}

British Medical fournal, 1972, 4, 146-149

\section{Summary}

Forty-two cases of ruptured hepatoma with intraabdominal haemorrhage were seen over a period of eight years in the professorial surgical unit at the Queen Mary Hospital, Hong Kong. In all, 207 cases of liver cancer were seen during this period, giving an incidence of rupture of $14.5 \%$. There were 37 men and five women. The clinical features were the sudden onset of pain with shock and the presence of blood in the peritoneal cavity. The diagnosis was made before operation on suspicion and by a process of elimination. In cases of doubt paracentesis abdominis was performed to determine whether there was blood in the peritoneal cavity. Treatment was directed to control of haemorrhage and resection.

The prognosis, although extremely poor, is no worse than the hepatocellular carcinoma that has not ruptured. There was one long-term survivor-a patient who had undergone an extensive resection. The man was alive and well after more than five years.

\section{Introduction}

On 23 April 1972 a Chinese man, aged 42, was admitted to the professorial surgical unit at the Queen Mary Hospital, Hong Kong. Ten days before admission he was seen in Britain with a history of a sudden upper abdominal pain. He was admitted to one of the local hospitals and at laparotomy the diagnosis was rupture of the hepatocellular carcinoma. The bleeding was from the carcinomatous nodules. An attempt to stop the haemorrhage by sutures failed and it was ultimately controlled by packing the liver with gauze. He was then flown back to Hong Kong and was admitted to this hospital for treatment. An emergency operation was carried out, and he was discharged from hospital six weeks after admission. We record the experience gained in dealing with such cases.

\section{Present Study}

Of 207 cases of liver cancer admitted to the professorial surgical unit from May 1964 to April 1972, 30 were admitted because of rupture with haemorrhage. In addition, 12 cases were referred

Queen Mary Hospital, University of Hong Kong, Hong Kong

G. B. ONG, O.B.E., F.R.C.S., Professor of Surgery

J. L. TAW, F.R.C.S., Lecturer in Surgery from the professorial medical unit. The number af cases of this tumour admitted to the professorial medical unit during this period was 451 . How many of them, either after discharge from hospital or found at postmortem examination, had actually ruptured is not known. Hence, the percentage calculation of ruptured hepatoma is based on the 30 cases admitted directly to the surgical wards. This gives an incidence of $14.5 \%$.

There were 37 males and 5 females, with a male to female ratio of $7 \cdot 4: 1$. The youngest patient was a boy aged 12 years and the oldest was a woman of 72. Most were in their third or fourth decade of life.

\section{CLINICAL FEATURES}

Pain.-This was present in all 42 cases $(100 \%)$. The onset of pain was sudden and severe and was situated at the epigastrium or the upper part of the abdomen and occasionally referred to the shoulders. There might be vomiting at the height of the pain. In some cases a feeling of distension in the upper abdomen was experienced for a period varying from a few weeks to one or two months. Then there would be sudden "bursting" pain which might be associated with the rapid onset of shock.

Shock.-Seventeen cases $(41 \%)$ were admitted in a state of shock with hypotension, pallor, and rapid pulse. The blood pressure varied from normal to non-recordable ones, but the average was $90 / 40 \mathrm{~mm} \mathrm{Hg}$.

Physical Findings. - On physical examination tenderness was present in 36 cases (85\%) and was usually confined to the upper part of the abdomen. Rebound tenderness, with a varying degree of abdominal rigidity, was also present. The lower abdomen was usually soft and non-spastic. In addition to the tenderness, a palpable mass connected with an enlarged liver was present in 27 cases $(64 \%)$. Palpation of the mass, if not too large, was rendered difficult by the presence of spasm in the upper part of the abdomen.

Haemoperitoneum.-Free fluid in the peritoneal cavity was detected in 33 cases $(78.6 \%)$. The fluid could have been due to the presence of free blood in the peritoneal cavity or to ascites. In cases of doubt paracentesis abdominis was carried out. In 21 of these cases abdominal tapping yielded frank blood or heavily blood-stained ascitic fluid.

In most of these cases, after diagnosis, preoperative preparation was carried out for emergency surgery. When first seen some were in hypovolaemic shock and required blood replacement. They seldom required sedatives as most had a relief of pain after the initial rupture.

Shock had to be combated, and when blood had been replaced and the blood pressure was stable early surgical intervention was undertaken. 